\title{
VIH/SIDA: Un tema de importancia en la salud comunitaria
}

\section{HIV/AIDS: Subject of importance in community health}

\author{
Karla H. Arce-Gil ${ }^{a}$, Malinquetzalli Huerta-De la Cruz ${ }^{b}$, María T. Sosa-Lozada $^{c}$
}

\begin{abstract}
:
The human immunodeficiency virus (HIV) is one that infects the cells of the immune system, altering or nullifying their function, which leads to the progressive deterioration of the same; there are 2 types (HIV-1 and VHI-2) of which the first has a greater distribution. Acquired immunodeficiency syndrome (AIDS) is the most advanced stage of HIV infection, presents marked symptoms, product of the deterioration of the immune system. HIV infection occurs around the world and its prevalence continues to rise. By the end of 2019, there were an estimated 38 million people living with HIV globally
\end{abstract}

Keywords:

Human immunodeficiency virus, acquired immunodeficiency syndrome, immune system impairment, T-lymphocytes, infection

\section{Resumen:}

El virus de inmunodeficiencia humana (VIH), es aquel que infecta a las células del sistema inmunitario, alterando o anulando su función, lo que lleva al deterioro progresivo del mismo; existen 2 tipos (VIH-1 y VHI-2) de los cuales el primero tiene una mayor distribución. El síndrome de inmunodeficiencia adquirida (SIDA) es la etapa más avanzada de la infección por VIH, presenta síntomas marcados, producto del deterioro del sistema immune. La infección por VIH se presenta alrededor de todo el mundo y su prevalencia continúa en aumento. Se estima que, a finales de 2019, había 38 millones de personas con el VIH a nivel mundial.

\section{Palabras Clave:}

Virus de inmunodeficiencia humana, síndrome de inmunodeficiencia adquirida, deterioro del sistema inmunitario, linfocitos T, infección

\section{Introducción}

Cuando se diagnosticó por primera vez el sida en Estados Unidos en 1981, los casos se identificaban al encontrar infecciones oportunistas graves como neumonía por Pneumocystis que indicaban defectos profundos de la inmunidad celular en ausencia de otras causas de inmunodeficiencia.[1] Una vez establecido el conocimiento de, VIH como causa del síndrome, resultó claro que las infecciones oportunistas graves, así como las neoplasias raras eran parte del espectro que guarda esta enfermedad. Por ello es importante tomar en cuenta los principales factores de riesgo: Contacto sexual con una persona infectada, exposición parenteral por recibir transfusiones con sangre infectada, compartir agujas o la exposición perinatal.

El VIH, que continúa siendo uno de los mayores problemas para la salud pública mundial, hasta el momento se ha cobrado ya casi 33 millones de vidas. Sin embargo, habida cuenta del acceso creciente a la prevención, el diagnóstico, el tratamiento y la atención

\footnotetext{
Autor de Correspondencia, Universidad Autónoma del Estado de Hidalgo, https://orcid.org/0000-0003-1586-148X, Email: ar278071@uaeh.edu.mx

${ }^{\mathrm{b}}$ Universidad Autónoma del Estado de Hidalgo, https://orcid.org/0000-0001-6855-2598, Email: hu383767@uaeh.edu.mx

c Universidad Autónoma del Estado de Hidalgo, Email: teresosa2000@yahoo.com
} 
eficaces del $\mathrm{VIH}$, incluidas las infecciones oportunistas, la infección por el VIH se ha convertido en un problema de salud crónico llevadero que permite a las personas que viven con el virus llevar una vida larga y saludable [2].

\section{Diagnóstico definitivo de SIDA (con o sin pruebas de laboratorio de infección por VIH}

1. Candidosis de esófago, tráquea, bronquios o pulmones.

2. Criptococosis extrapulmonar.

3. Criptosporidiosis con diarrea que persiste más de un mes.

4. Citomegalovirosis en un órgano diferente del hígado, bazo o ganglios linfáticos.

5. Infección por herpes simple causante de una úlcera mucocutánea que persiste más de un mes; o bronquitis, neumonía o esofagitis de cualquier duración.

6. Sarcoma de Kaposi en un paciente $<60$ años.

7. Linfoma cerebral (primario) en un paciente $<60$ años.

8. Enfermedad diseminada por Mycobacterium kansasii o el complejo Mycobacterium avium (en un sitio diferente o además de los pulmones, piel o ganglios linfáticos cervicales o hiliares).

9. Neumonía por Pneumocystis jirovecii.

10. Leucoencefalopatía multifocal progresiva.

11. Toxoplasmosis cerebral.

Tabla 1. Definición de los CDC de los casos de sida para la detección en adultos y adolescentes.

En México la prevalencia de infección por $\mathrm{VIH}>5 \%$,

El número de casos acumulados para el año 2020 fue de: 89,005; el número de casos nuevos fue de: 8,635 ; de entre los estados de la republica aquellos con la mayor tasa de casos nuevos de VIH fueron: Quintana Roo, Colima, Yucatán, Veracruz y Morelos [3].

\section{Definiciones}

La definición de casos de SIDA, según los Centers for Disease Control and Prevention (CDC) (Tabla 1), incluye infecciones oportunistas y cánceres que rara vez ocurren en ausencia de inmunodeficiencia grave (como neumonía por Pneumocystis, linfoma del sistema nervioso central). También clasifica como personas con SIDA a quienes tienen un estudio serológico positivo para VIH y ciertas infecciones y cánceres que pueden aparecer en hospedadores con buena respuesta inmunitaria, pero que son más frecuentes en individuos infectados por $\mathrm{VIH}$ (tuberculosis pulmonar, cáncer cervicouterino invasor).

La definición incluye criterios para los diagnósticos definitivo y preliminar de ciertas infecciones $y$ tumoraciones. Por último, se asume que los sujetos con estudio serológico positivo para VIH que alguna vez tuvieron recuentos de linfocitos $<200 / \mu l$ o un porcentaje de linfocitos CD4 <14\% tienen sida. La inclusión de personas con cifras bajas de CD4 como casos de sida refleja el reconocimiento de que la inmunodeficiencia es la característica definitoria del trastorno [4].

\section{Fisiopatología}

El distintivo principal de la enfermedad por VIH es una marcada inmunodeficiencia que es el resultado de una deficiencia progresiva de linfocitos $\mathrm{T}$ cooperadores, definidos por su expresión de superficie celular con moléculas CD4, mismas que sirven como receptor celular primario para el $\mathrm{VIH}$.

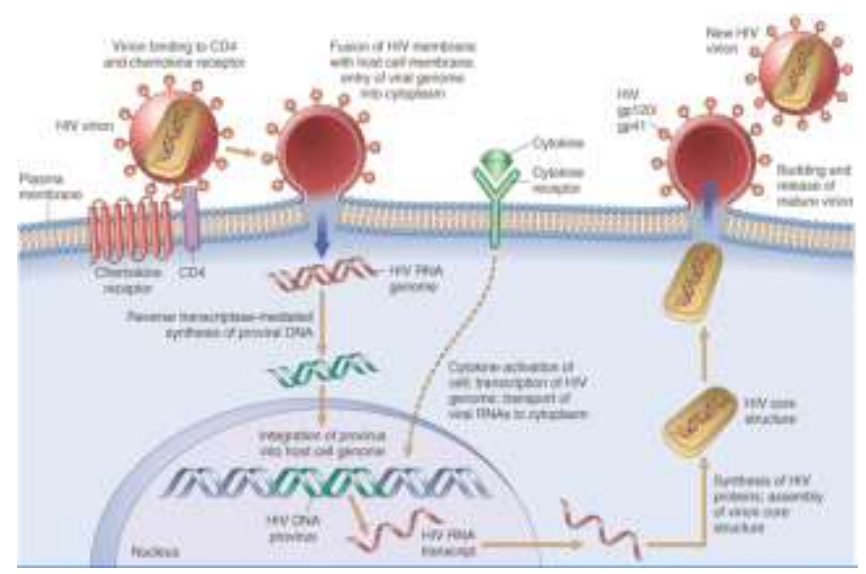

Imagen 1. Mecanismo de infección por VIH-1 (Tomada de internet)

Como se observa en la imagen 1, después de la transmisión inicial, el virus infecta las células CD4+, predominantemente los linfocitos $\mathrm{T}$, pero también los monocitos o células dendríticas derivadas de la médula ósea. Tanto durante esta etapa inicial como más tarde en la infección, el sistema linfoide es un sitio importante para el establecimiento y la propagación de la infección por VIH. El tejido linfoide asociado al intestino (GALT, gutassociated lymphoid tissue) cumple una función en el establecimiento de la infección y en la reducción precoz de los linfocitos T CD4+ de memoria [5].

También se establece un estado latente, con la integración del genoma del VIH en el genoma de la célula. La célula que más se infecta es el linfocito CD4 (colaborador-inductor), que dirige a muchas otras células en la red inmunitaria. Al prolongarse la infección, el número de linfocitos CD4 disminuye. 


\section{Manifestaciones clínicas}

Las complicaciones de las infecciones y las neoplasias relacionadas con el VIH afectan a casi todo el organismo. La estrategia general para abordar a la persona infectada por VIH que presenta síntomas consiste en la valoración de los órganos, aparatos y sistemas afectados a fin de diagnosticar con rapidez las alteraciones tratables.

Como puede observarse en la imagen 2 , el recuento de linfocitos CD4 permite al médico enfocarse en los diagnósticos más probables que corresponden a cada etapa de la inmunodeficiencia. Pueden aparecer ciertas infecciones con cualquier cifra de CD4, mientras que otras raras veces se presentan, a menos que el recuento de linfocitos CD4 descienda por debajo de cierta concentración [6].

Imagen 2. Relación del recuento de CD4 con la aparición de infecciones oportunistas

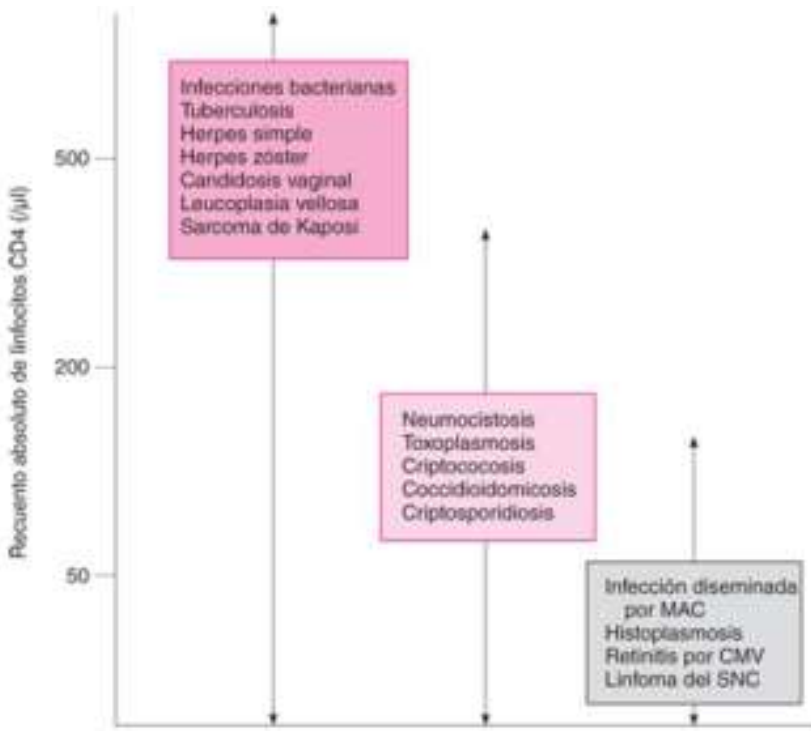

(Fuente: Maxine A. Papadakis, Stephen J. McPhee Diagnóstico clínico y tratamiento, 2017)

\section{Signos y síntomas:}

Muchos individuos con infección por VIH se mantienen asintomáticos durante años, incluso sin tratamiento antirretroviral, con un tiempo promedio de casi 10 años entre la exposición y la aparición del sida. Cuando surgen los síntomas, son muy variables e inespecíficos. Puesto que casi todas las manifestaciones pueden ocurrir con otras enfermedades, una combinación de ellas es más indicativa de infección por VIH que algún síntoma aislado. La exploración física puede ser por completo normal. Los hallazgos de anomalías son diversos, desde los del todo inespecíficos hasta los muy específicos de infección por $\mathrm{VIH}$. Estos últimos incluyen leucoplasia vellosa de la lengua, sarcoma de Kaposi diseminado y angiomatosis bacilar cutánea. La linfadenopatía generalizada es frecuente en las primeras etapas de la infección [4].

\section{Diagnóstico}

El diagnóstico de infección por el $\mathrm{VIH}$ se basa en la demostración de los anticuerpos anti-VIH, en la detección directa del VIH o de alguno de sus componentes, o en ambos [7].

La infección por el virus de la inmunodeficiencia humana (VIH-1) debe diagnosticarse mediante una prueba rápida de VIH o una prueba convencional de ensayo por inmunoabsorción ligada a enzima (ELISA) y confirmada mediante ensayo Western blot o por inmunofluorescencia indirecta [8].

En todo paciente con sospecha de VIH se le debe hacer una evaluación inicial con el objetivo de confirmar el diagnóstico de la infección por el VIH y obtener toda la información necesaria clínica y de laboratorio [8].

La evaluación inicial del paciente con infección por el VIH debe incluir:

- Interrogatorio clínico completo.

- Examen físico completo (incluir peso, talla, índice masa-corporal, presión arterial y circunferencia de cintura).

- Evaluación cardiovascular (investigar tabaquismo, hipertensión arterial, diabetes mellitus, evaluación de lípidos, etc.).

- Investigación de infecciones de transmisión sexual.

- Evaluación de riesgos para infecciones oportunistas que requieran profilaxis.

- Evaluación de su condición social, psicológica y neurológica.

- Valorar la necesidad de aplicación de inmunizaciones contra Hepatitis A, B, influenza y neumococo y anualmente de influenza.

- Efectuar la prueba cutánea de PPD, sobre todo en población de alto riesgo [7].

\section{Tratamiento}

Tratamiento antirretroviral:

$>$ Inhibidores nucleosídicos de la transcriptasa inversa (ITIN): Tenofovir (TDF), Emtricitabina (FTC), Abacavir (Ziagen), Lamivudina (3TC), Estavudina (d4T), Didanosina (ddl) (Videx), Zidovudina (AZT) (Retrovir)

> Inhibidores no nucleosídicos de la transcriptasa inversa (ITINN): Delavirdina (Rescriptor), Efavirenz 
(Sustiva), Etravirina (Intelece), Nevirapina (Viramune), Rilpivirina (Edurant).

$>$ Inhibidores de la proteasa (IP): Ritonavir (Norvir), Atazanavir (Reyataz) (ATZ), Darunavir (Prezista), Abacavir (ABC), Lopinavir (LPV/r).

$>$ Inhibidores de la entrada (IE): Enfuvirtida (Fuzeon) Maraviroc (Selzentry)

$>$ Inhibidores de la integrase: Raltegravir (Isentress) Elvitegravir (Stribild) Dolutegravir (Tivicay)

El esquema de tratamiento está conformado por: 2 ITIN + 1 ITINN o 1 IP.

Los fármacos de elección son: Tenofovir (TDC) y Emtricitabina (FTC) + Efavirenz (EFV) o Atazanavir, Ritonavir.

Otras opciones:

$>$ Abacavir (ABC) Lamivudina (3TC) $($ LMV) + Nevirapina (NVP) o Lopinavir Ritonavir

$>$ Zidovudina (AZT) (ZDV) Lamivudina (3TC) (LMV) + Nevirapina (NVP) o Fosamplenavir, Ritonavir

En embarazadas:

$>$ Zidovudina $(\mathrm{AZT})+$ Lamivudina $(3 \mathrm{TC})+$ Nevirapina (NVP).

Recién nacido:

> Madre con buen control prenatal y carga viral indetectable: AZT (desde el nacimiento hasta las 6 semanas de vida extrauterina

$>$ Madre con mal control prenatal o diagnostico durante el parto: triple terapia AZT + 3TC + NVP [9].

\section{Prevención}

Medidas generales:

$\checkmark \quad$ Evitar prácticas sexuales de riesgo

$\checkmark \quad$ Uso de métodos anticonceptivos de barrera

$\checkmark$ Donadores de sangre habituales: Pruebas de detección de VIH

Prevención de la transmisión ocupacional:

- Equipo de protección personal

- Lavado de manos y superficies de la piel inmediatamente después del contacto con sangre o fluidos corporales.

- Cuidado al manipular y desechar instrumentos afilados durante y después de su uso.

- Dispositivos de seguridad para evitar lesiones por pinchazos con agujas.
- Desechar las jeringas e instrumentos afilados en un recipiente para objetos punzantes.

En caso de probable exposición ocupacional se deben realizar:

- Exprimir la herida

- Lavado con agua y jabón

- Acudir al servicio médico hospitalario

- Informar el incidente por escrito

- Muestra sanguínea basal: VIH, VHB, VHC

- Medidas para determinar si realmente se encuentra infectado

- Recomendar sexo seguro

- Tratamiento profiláctico dentro de las 4 horas posteriores

- Manejo Antirretroviral

- Muestras sanguíneas: 3, 6, 12 meses para vigilar seroconversión

Profilaxis post exposición al VIH (PPE-VIH):

$>$ Exposiciones habituales: 2 análogos de nucleósidos inhibidores de la transcriptasa inversa por 4 semanas

> Exposiciones de alto riesgo o complicadas: 2 análogos de nucleósidos inhibidores de la transcriptasa inversa. + Inhibidor de la proteasa por 4 semanas [10].

\section{Conclusión}

A pesar de las extensas investigaciones realizadas sobre el tema, no se ha descubierto cura alguna para el $\mathrm{VIH} / \mathrm{SIDA}$. Existen tratamientos como los antes mencionados, que evitan la replicación del virus y realentizan el avance de la enfermedad, sin embargo, el $\mathrm{VIH}$ causa lentamente el deterioro del sistema inmunológico, al punto de tornarse irreversible, permitiendo la infección por más infecciones oportunistas que pueden conducir al paciente hasta la muerte. Por ello, es importante informar a la población sobre los factores de riesgo y las medidas de prevención hacia esta enfermedad.

\section{Referencias}

[1] Reitz m, Gallo R. Virus de la inmunodeficiencia humana. En: Bennet J, Dolin R, Blaser M. Mandell, Douglas, and Bennett's Principies and Practice oflnfectious Diseases. $8^{\circ}$ edición. Barcelona: Elsevier España, S.L.U. 2016.

[2] Organización mundial de la Salud VIH/SIDA [internet]. OMS 2021 [citado 27 may 2021] disponible en: https://www.who.int/es/newsroom/fact-sheets/detail/hiv-aids

[3] Dirección de vigilancia epidemiológica de enfermedades transmisibles [internet]. Secretaria de salud, Gobierno de México. 2020. Sistema de vigilancia epidemiológica de VIH informe histórico al 4to trimestre de vih 2020. [citado 28 may 2021] disponible en: 
Publicación semestral, Educación y Salud Boletín Científico Instituto de Ciencias de la Salud Universidad Autónoma del Estado de

Hidalgo, Vol. 9, No. 17 (2021) 93-97

https://www.gob.mx/cms/uploads/attachment/file/622468/VIH-

Sida_4toTrim_2020.pdf

[4] Papadakis M. Capítulo 31: Infección por VIH y SIDA. En: Diagnístico clínico y tratamiento, 2017. 56a ed. Ciudad de México: McGraw Hill; 2017. p. 1331-1340.

[5] Kaspel D. CAPÍTULO 107: Infección por VIH y sida. En: Harrison. Manual de Medicina. 19a ed. Ciudad de México: McGraw Hill; 2017. p. $554-567$.

[6] Papadakis M. Capítulo 31: Infección por VIH y SIDA. En: Diagnístico clínico y tratamiento, 2017. 56a ed. Ciudad de México: McGraw Hill; 2017. p. 1331-1336.

[7] Jameson, J., Fauci, A., Kasper, D., Hauser, S., Longo, D., \& Loscalzo, J. (2015). Harrison. Principios de Medicina Interna. Vol.2 (19 a ed.). Nueva York: Mc Graw Hill

[8] Diagnóstico y referencia oportuna del paciente con infección por el VIH en el primer nivel de atención. Guía de práctica clínica. México: Guía de referencia rápida.

[9] Tratamiento antirretroviral del paciente adulto con infección por el VIH Guía de práctica clínica. México: Evidencias y recomendaciones.

[10] Paraguay. Ministerio de Salud Pública y Bienestar Social. Programa Nacional de Control de VIH/ITS (PRONASIDA). Recomendaciones básicas: profilaxis post-exposición ocupacional al VIH, Virus de la hepatitis B y C y normas de bioseguridad. ( $3^{\mathrm{a}}$ ed.) Asunción: OPS, 2010. 